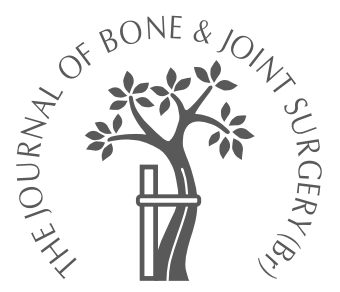

R. Itayem,

A. Arndt,

L. Nistor,

D. McMinn,

A. Lundberg

From the Karolinska Institute, Stockholm, Sweden

\title{
Stability of the Birmingham hip resurfacing arthroplasty at two years
}

\author{
A RADIOSTEREOPHOTOGRAMMETRIC ANALYSIS STUDY
}

R. Itayem, MD,

Orthopaedic Surgeon

A. Arndt, PhD, Assistant

Professor

A. Lundberg, MD, PhD,

Associate Professor,

Consultant Orthopaedic

Surgeon

Department of Orthopaedic

Surgery, Karolinska Institute,

Karolinska University

Hospital/Huddinge, SE-

14186 Stockholm, Sweden.

L. Nistor, MD, PhD,

Consultant Orthopaedic

Surgeon

Department of Orthopaedics,

Nuclear Hospital, SE-54185

Skövde, Sweden.

D. McMinn, MD,

Consultant Orthopaedic

Surgeon

Birmingham Nuffield

Hospital, 22 Somerset Road,

Edgbaston, Birmingham B15

2QQ, UK.

Correspondence should be sent to Dr R. Itayem; e-mail: itayem_r@hotmail.com

(C)2005 British Editorial Society of Bone and Joint Surgery

doi:10.1302/0301-620X.87B2. $15394 \$ 2.00$

$J$ Bone Joint Surg [Br] 2005;87-B:158-62.

Received 16 February 2004;

Accepted 24 March 2004

The Birmingham hip resurfacing metal-on-metal arthroplasty was introduced in 1997 and has shown promising short- to mid-term results. We used radiostereophotogrammetric analysis (RSA) to study the stability of $\mathbf{2 0}$ resurfacing arthroplasties over a follow-up period of 24 months.

Radiological examinations for RSA were performed immediately after surgery and at two, six, 12 and 24 months after operation. Precision and detection of migration thresholds (non-zero movement) were calculated.

All the results corresponded well to those found in similar experimental arrangements with standard hip prostheses. Migration of the cup and vertical and mediolateral migration of the head were calculated. The values were low at two years compared with those of earlier studies of cemented femoral components in conventional total hip replacements indicating that there was no evidence of excessive early migration or loosening of the components.

Conservation and restoration of the anatomy and biomechanical function are fundamental goals of orthopaedic surgery. A perceived advantage of surface replacement of the hip is that the natural anatomy is better replicated than with the more traditional total hip replacement. The first metal-on-metal, double-cup arthroplasties were performed by Müller. ${ }^{1}$ The socket was made of polished cobalt-chrome with a small polar protuberance which was press-fitted into the acetabulum after reaming. The femoral component was a hemispherical shell which, after reaming, was pressed onto the femoral head. In a series of 18 patients described in 1968, the prosthesis functioned satisfactorily in one patient for at least 14 years. ${ }^{1}$

In the 1970s, total resurfacing hip arthroplasty using a polyethylene cup and a metal head gained in popularity. ${ }^{2-8}$ However, high rates of failure resulted in the procedure being abandoned. ${ }^{9}$ It is established that, for most designs of implant, the main threat to longterm fixation is debris from polyethylene bearings. Among the methods used to address the problem, the use of metal surfaces for both the acetabular and the femoral components has been one of the most promising. ${ }^{10}$ The heattreated McMinn prosthesis ${ }^{10}$ was a metal-onmetal resurfacing prosthesis with a cemented femoral component and an uncemented hydroxyapatite-coated acetabular component which was designed in the late 1980s. In 1997 the Birmingham hip resurfacing (BHR) arthroplasty ${ }^{11}$ (Fig. 1) was introduced in which heat treatment was abandoned in favour of an 'as-cast' state of the cobalt-chrome alloy. This was considered to be superior from a metallurgical point of view. The BHR has been used in limited clinical practice for 6.5 years with promising short- to mid-term clinical and radiological results. ${ }^{12}$

Radiostereophotogrammetric analysis (RSA) is an indispensable tool in the assessment of the migration of implants. Its main advantage is its accuracy, with a threshold of detection of translation up to ten times better than that of conventional radiography. This allows unexpected patterns of migration to be identified over short follow-up periods and it is invaluable in the early recognition of the necessity for revision. ${ }^{13,14}$ However, the geometry of the BHR arthroplasty does not provide the optimal rigid-body characteristics for RSA and, in addition, the accuracy of this analysis has not previously been assessed for resurfacing implants. We now report our results using RSA to determine the stability of the BHR implant over a period of 24 months.

\section{Patients and Methods}

Between November 1999 and January 2000, 19 consecutive male patients underwent hip resurfacing with a BHR arthroplasty. One had 
bilateral resurfacing, giving a total number of implants of 20. All the operations were performed by the same surgeon (DM). The implants were equipped with tantalum markers on titanium towers (Fig. 1). During the operation, additional markers (six to eight per segment) were introduced into the pelvis and femur (Fig. 1). Radiological examinations for RSA were performed immediately post-operatively and at two, six, 12 and 24 months after operation. Because of the large quantity of metal present in the images, the X-ray tubes were placed within a very limited range of position. One tube provided an almost pure anteroposterior view while the other was inclined cranially (Fig. 2).

The two-dimensional positions of every implant and skeletal marker in each radiograph were digitised and their three-dimensional coordinates were calculated using standard RSA software (RSA Biomedical, Umeå, Sweden). Migrations were calculated using the kinematics software which was provided in the same package. The centre of the acetabular cup in the post-operative examination was calculated as an approximation of the centre of the head of the implant. The cup was used because of the difficulties which we encountered in making an elliptic fit onto the small portion of the surface of the head which was visible on the radiographs. The centre of the cup was considered to approximate to the centre of the head with sufficient accuracy to allow a description of migration of the head. The cup was only used in the first examination. In later examinations this point was recreated from markers which had been fixed to the femoral component. In addition to all migrations being described in relation to the global co-ordinate system, with one axis aligned to the long axis of the $\mathrm{X}$ ray table, a second axis being mediolateral and a third being anteroposterior, migration of the centre of the head was also recalculated in relation to the axial direction of the femoral neck.

The accuracy of the non-zero movement of the RSA technique was tested on pairs of radiographs taken on the same occasion but separated in time by approximately five minutes. This allowed the patient to move, while the relative movement between the implant and bone segments theoretically remained equal to zero. Any movement of the implant which was calculated between exposed pairs on the same occasion was therefore an error of non-zero movement. Multiple exposures were taken only if the initial exposures indicated difficulties in identification of the markers, primarily those of the cup. It was only when such additional exposures were undertaken that the redundant image pairs which were necessary for this reliability study were made available.

\section{Results}

Precision and migration detection threshold. The calculated mean errors of non-zero movement between duplicate RSA examinations performed on the same occasion are shown in Table I. The relevant SDs are included as reference data in the results of migration of the BHR.



Fig. 1

Radiograph with markers visible in the calibration device (812-892), pelvis (11-18), femur (41-46), acetabular component (21-23) and femoral component (31-33). The configuration of the acetabular component has two rim markers and one polar marker.



Fig. 2

Diagram of the problem of depicting the polar marker on two radiographic views.

Migration of the cup. Migration values for the cup over time were small (Table II, Fig. 3). There was no consistent pattern of proximal migration.

Migration of the head. Values for rotation of the femoral component were small (Table III) as were those for its 
Table I. The mean error (95\% confidence interval) error of non-zero movement of the cup relative to the pelvis, the femoral component relative to the femur and the point calculated in the femoral component relative to the femur

\begin{tabular}{lllll}
\hline & Axis & Cup & Head & Point \\
\hline Rotation ( $\left.{ }^{\circ}\right)$ & Mediolateral & $0.253(0.084)$ & $0.459(0.111)$ & \\
& Distal proximal & $0.201(0.083)$ & $0.466(0.112)$ & \\
Translation (mm) & Anteroposterior & $0.074(0.022)$ & $0.155(0.036)$ & \\
& Mediolateral & $0.035(0.011)$ & $0.118(0.038)$ & $0.107(0.035)$ \\
& Distal proximal & $0.048(0.019)$ & $0.108(0.029)$ & $0.083(0.018)$ \\
& Anteroposterior & $0.092(0.027)$ & $0.156(0.032)$ & $0.329(0.098)$ \\
& Resultant & & & $0.383(0.098)$ \\
\hline
\end{tabular}

\begin{tabular}{|c|c|c|c|c|c|}
\hline & \multirow[b]{2}{*}{ Axis } & \multicolumn{4}{|c|}{ Time interval after surgery (mths) } \\
\hline & & 2 & 6 & 12 & 24 \\
\hline \multirow[t]{3}{*}{ Rotation ( ${ }^{\circ}$ ) } & Mediolateral & $0.128(0.608)$ & $0.241(0.618)$ & $0.199(0.650)$ & $0.213(0.716)$ \\
\hline & Distal proximal & $0.069(0.349)$ & $0.020(0.357)$ & $0.025(0.366)$ & $0.150(0.391)$ \\
\hline & Anteroposterior & $0.052(0.312)$ & $0.069(0.304)$ & $-0.002(0.352)$ & $0.048(0.352)$ \\
\hline \multirow[t]{3}{*}{ Translation (mm) } & Mediolateral & $-0.018(0.112)$ & $-0.006(0.098)$ & $-0.019(0.210)$ & $-0.080(0.155)$ \\
\hline & Distal proximal & $0.081(0.096)$ & $0.075(0.106)$ & $0.054(0.096)$ & $0.048(0.105)$ \\
\hline & Anteroposterior & $-0.001(0.240)$ & $0.021(0.264)$ & $-0.045(0.266)$ & $-0.048(0.309)$ \\
\hline
\end{tabular}

Table III. Mean (SD) rotations ( ${ }^{\circ}$ ) of the femoral component. Positive values indicate extension (equivalent to hip extension), internal rotation and adduction. All movements are of the femoral component in relation to the femur

\begin{tabular}{llrll}
\hline \multirow{2}{*}{ Axis } & \multicolumn{4}{l}{ Time interval after injury (mths) } \\
\cline { 2 - 5 } & $\mathbf{2}$ & $\mathbf{6}$ & $\mathbf{1 2}$ & $\mathbf{2 4}$ \\
\hline Mediolateral & $0.037(0.564)$ & $0.001(0.757)$ & $0.155(0.469)$ & $0.018(0.488)$ \\
Distal proximal & $0.134(0.690)$ & $-0.021(0.996)$ & $0.101(0.850)$ & $0.064(0.712)$ \\
Anteroposterior & $-0.078(0.217)$ & $0.060(0.180)$ & $0.013(0.191)$ & $0.001(0.224)$ \\
\hline
\end{tabular}

migration along the vertical axis. The pattern of migration over time indicated limited subsidence (Table IV, Fig. 4). Values for migration in a mediolateral direction were also small, as were those for migration calculated in the direction of the femoral neck (Table IV, Fig. 5). No consistent pattern over time was detected.

The non-optimal marker configuration used for the BHR arthroplasty gave the greatest non-zero movement around the femoral longitudinal axis $\left(0.466^{\circ}\right.$ of rotation). This had the largest $95 \%$ confidence interval (CI) of $0.112^{\circ}$. The femoral component had the lowest error along the vertical axis $(0.108 \mathrm{~mm})$ and also the lowest $95 \%$ CI of $0.029 \mathrm{~mm}$. The cup was well identified by the three attached markers if the $\mathrm{X}$-ray tubes were positioned at angles which ensured that all three markers were visible. Furthermore, the definition of the femoral component by the calculation of a single point within the femoral head provided high accuracy in translation along both the mediolateral and proximal distal axes of $0.107 \mathrm{~mm} \mathrm{(95 \%} \mathrm{CI} 0.035)$ and $0.083 \mathrm{~mm}(95 \%$ CI $0.018)$, respectively. All the results for non-zero movement corresponded well to those presented in a similar experimental arrangement with standard hip prostheses. ${ }^{15}$ Migration values for the cup were small in all planes in our study.

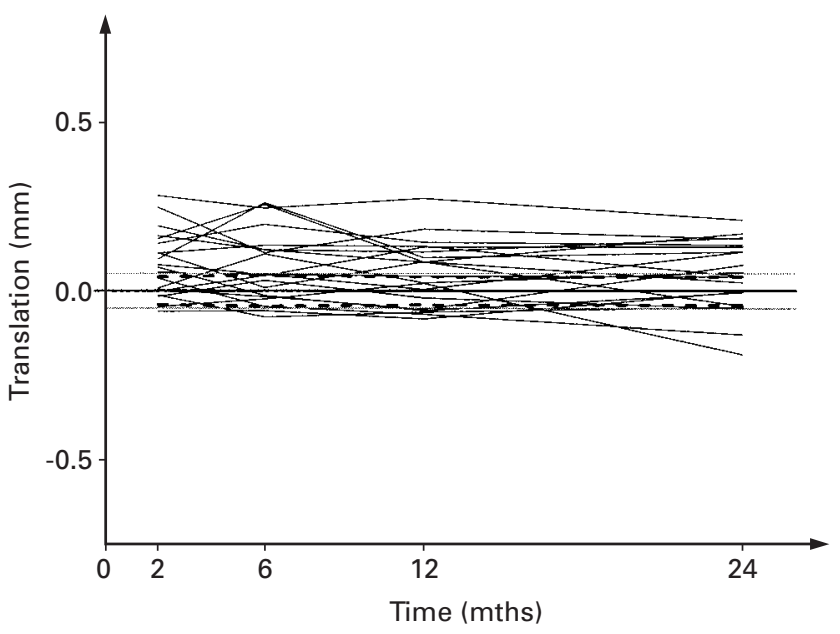

Fig. 3

Graph of vertical migration of the cup over time. The heavy, dashed lines indicate $0 \pm 95 \%$ confidence interval $(\mathrm{Cl})$ and the pale, extended lines indicate $0 \pm$ SD calculated from the determination of the zero-movement. Although migration can be assumed to be 0 at time 0 (post-operative examination), the estimation of error indicates that the span of observed migration values is similar irrespective of the time interval between the first two examinations. Because of this we have chosen not to connect the observed two-month positions to the origin of the translation time plot. 
Table IV. Mean (SD) translation $(\mathrm{mm}$ ) of the centre of the head. Positive values indicate medial, cranial and anterior translation. All movements are of the calculated prosthetic centre of the head in relation to the femur

\begin{tabular}{lllll}
\hline \multirow{2}{*}{ Axis } & \multicolumn{4}{l}{ Time interval after surgery (mths) } \\
\cline { 2 - 5 } & $\mathbf{2}$ & $\mathbf{6}$ & $\mathbf{1 2}$ & $\mathbf{2 4}$ \\
\hline Mediolateral & $-0.008(0.188)$ & $-0.060(0.244)$ & $-0.071(0.254)$ & $-0.113(0.232)$ \\
Distal proximal & $0.037(0.122)$ & $0.052(0.171)$ & $0.038(0.150)$ & $-0.040(0.161)$ \\
Anteroposterior & $0.046(0.422)$ & $-0.101(0.714)$ & $-0.191(0.604)$ & $-0.023(0.506)$ \\
Along neck & $-0.028(0.096)$ & $-0.071(0.174)$ & $-0.055(0.177)$ & $-0.024(0.176)$ \\
\hline
\end{tabular}

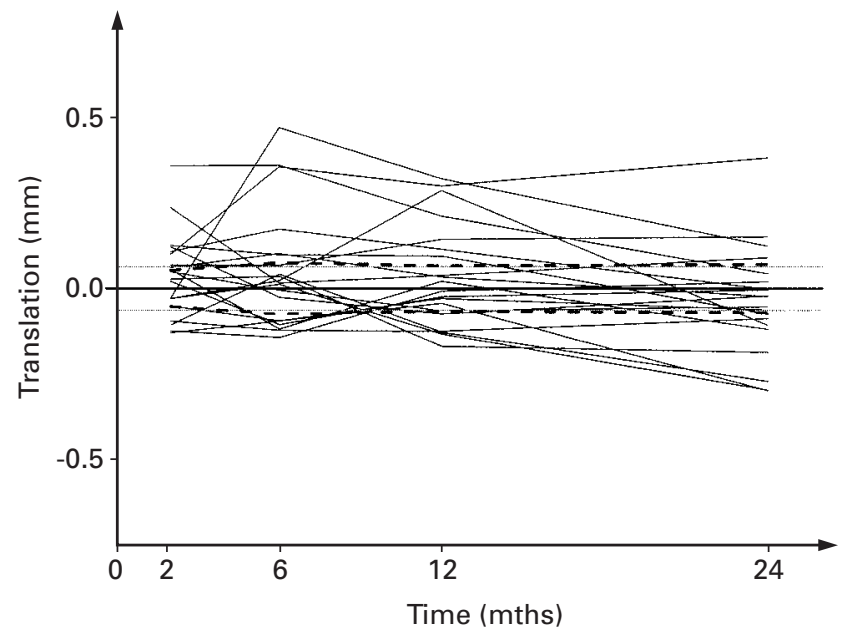

Fig. 4

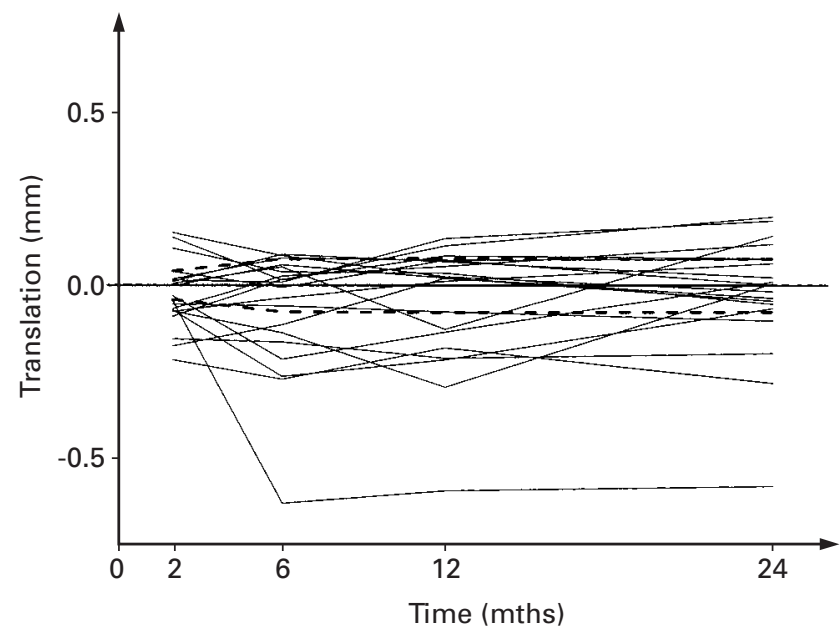

Fig. 5

Graph of vertical migration of the femoral component over time. The heavy, dashed lines indicate $0 \pm 95 \% \mathrm{Cl}$ and the pale, extended lines indicate $0 \pm$ SD calculated from the determination of zero-movement. See legend of Figure 3 for an explanation of absence of plot between time 0 and two months.

This corresponded to values in earlier studies of press-fit acetabular cups. ${ }^{13}$

\section{Discussion}

Hip resurfacing arthroplasty was used during the 1970s and early 1980s with discouraging results. Although the main reasons for the earlier failures of metal-on-metal resurfacing have now been addressed, new implants must be carefully analysed. Migration is one of the most consistent indicators of failure for arthroplasties in general. ${ }^{13}$ In total hip replacement a subsidence level of $1.2 \mathrm{~mm}$ of the stem after two years has been shown to be a strong indicator of early or mid-term revision. ${ }^{16}$ For hip resurfacing, no studies of migration patterns have been published. There is also no available information on which indicators of failure are present in terms of the direction and magnitude of translation and rotation.

In conventional hip replacement surgery, subsidence and internal rotation are major indicators of failure and the vertical axis coincides with the long axis of the implant.

For hip resurfacing, both the vertical axis and the long axis of the neck of the femur are possible directions of subsidence. We therefore calculated translation in relation to the long axis of the neck as well as to the axes of the anatomical co-ordinate system. There was no pattern of migration in relation to the long axis of the neck $(-0.024 \pm 0.176 \mathrm{~mm}$ after 24 months), and the values were low in comparison with the measurement error. Values for vertical migration were similarly low $(-0.040 \pm 0.161 \mathrm{~mm}$ after 24 months $)$ and there was no significant pattern, although the curve showed a slight inclination by the end of our study. We found that measurements of anteroposterior translation of the femoral component corresponded to external-internal rotation of a conventional total hip replacement and showed higher values of error than the other directions of migration (maximum SD $0.714 \mathrm{~mm}$ at six months). This can be attributed to a combination of a limited distance between the X-ray tubes and the configuration of the three head segment markers. Six patients showed a pattern of posterior translation greater than the migration detection 
threshold of $0.329 \mathrm{~mm}$ (95\% CI 0.098), but with no consistent pattern.

In several previously studied implants, particularly uncemented ones, a pattern of early migration along the loading direction was observed which subsequently ceased ('settling in'). We did not see such a pattern in our study, although in one patient a comparatively large migration along the long axis of the neck was seen between the twoand six-month examinations.

Our study shows that migration values at two years are small when compared with earlier studies of uncemented acetabular cups and cemented femoral components in total hip arthroplasty. However, there are other possible modes of failure of the BHR arthroplasty which remain to be analysed using other methods.

No benefits in any form have been received or will be received from a commercial party related directly or indirectly to the subject of this article.

\section{References}

1. Schmalzried T, Fowble V, Ure K, Amstutz H. Metal on metal surface replacement of the hip: technique, fixation and early results. Clin Orthop 1996;329(Suppl):106-14.

2. Paltrinieri M, Trentani C. A modification of the hip arthroprosthesis. Chir Organi Mov 1971;60:85-95.

3. Amstutz H, Graff-Radford A, Gruen T, Clarke I. Tharies surface replacements: a review of the first 100 cases. Clin Orthop 1978;134:87-101.
4. Capello W, Ireland P, Trammell T, Eicher P. Conservative total hip arthroplasty: a procedure to conserve bone stock: part I: analysis of sixty-six patients: part II: analysis of failures. Clin Orthop 1978;134:59-74.

5. Furuya K, Tsuchiya H, Kawachi S. Socket-cup arthroplasty. Clin Orthop 1978;134: 41-4.

6. Tanaka S. Surface replacement of the hip joint. Clin Orthop 1978;134:75-9.

7. Wagner H. Surface replacement arthroplasty of the hip. Clin Orthop 1978;134: 102-30.

8. Freeman M, Cameron H, Brown G. Cemented double cup arthroplasty of the hip: a 5 year experience with the ICLH prosthesis. Clin Orthop 1978;134:45-52.

9. Amstutz H. Surface replacement arthroplasty. Edinburgh: Churchill-Livingstone, 1991:295-32.

10. McMinn D, Treacy R, Lin K, Pynsent P. Metal on metal surface replacement of the hip: experience of the McMinn prosthesis. Clin Orthop 1996;329Suppl:89-98.

11. Daniel J, Pynsent PB, McMinn D. Metal-on-metal resurfacing of the hip in patients under the age of 55 years with osteoarthritis. J Bone Joint Surg [Br] 2004; 86-B:177-84

12. McMinn D, Pynsent P. Metal/metal hip resurfacing with hybrid fixation: results of 1000 cases: a personal series [abstract]. Procs American Academy of Orthopaedic Surgeons, 2001.

13. Kärrholm J, Herberts $\mathbf{P}$, Hultmark $\mathbf{P}$, et al. Radiostereometry of hip prostheses: review of methodology and clinical results. Clin Orthop 1997;344:94-110.

14. Kärrholm J, Malchau H, Snorrason F, Herberts P. Micromotion of femoral stems in total hip arthroplasty: a randomised study of cemented, hydroxyapatite-coated, and porous-coated stems with roentgen stereophotogrammetric analysis. J Bone Joint Surg [Am] 1994;76-A:1692-705.

15. Börlin N, Thien T, Kärrholm J. The precision of radiostereometric measurements: manual vs. digital measurements. J Biomech 2002;35:69-79.

16. Kärrholm J, Borssèn B, Löwenhielm G, Snorrason F. Does early micromotion of femoral stem prostheses matter?: 4-7 year stereophotogrammetric analysis. J Bone Joint Surg [Br] 1994;76-B:912-17. 